\title{
Educação para todos: da nova escola às jornadas de junho
}

Roberta Muriel Cardoso

Doutorado em Educação - Universidade de Sorocaba

Professora do Mestrado na Faculdade Pedro Leopoldo

roberta.muriel@fpl.edu.br

Domingos Antonio Giroletti

Doutorado em Antropologia Social pelo Museu Nacional/UFRJ.

Professor do Mestrado na Faculdade Pedro Leopoldo

domingosgiroletti@gmail.com

\section{Editor Científico: José Edson Lara}

Organização Comitê Científico

Double Blind Review pelo SEER/OJS

Recebido em 18.10.2018

Aprovado em 20.11.2018 


\title{
Resumo
}

As jornadas de junho e as manifestações realizadas no Brasil em 2015 e 2016 são externalizações de desejos profundos da sociedade por mobilidade social, democratização do país e por instituições mais republicanas. Na elaboração desta pensata foram usadas informações provenientes de três fontes de pesquisa: a bibliográfica, a documental e a mídia institucional e alternativa. Foram discutidas a proposta de Anísio Teixeira para implantar a "nova escola", uma educação pensada para todos como um processo democrático. Em um segundo momento, discutiu-se também a "democratização do acesso" ao ensino superior. Por fim, foi traçado um paralelo entre a luta pela democratização do país no passado e no presente. Palavras-chave: Democratização, Escola Nova, Educação Básica e Superior, Jornadas de Junho.

\section{Education for all: from the new school to the June days.}

\begin{abstract}
The June Days and the demonstrations held in Brazil in 2015 and 2016 are externalizations of deep desires of society for social mobility, democratization of the country and more republican institutions. In the elaboration of this thought out we used information from three research sources: the bibliographical, the documentary and the institutional and alternative media. The proposal of Anísio Teixeira to implement the "new school" was discussed, an education designed for all as a democratic process. In a second step, it also discussed the meaning of the "democratization of access" to higher education. Finally, a parallel was drawn between the struggle for the democratization of the country in the past and the present.
\end{abstract}

Keywords: Democratization, New School, Basic and Higher Education, June Days.

\section{Educación para todos: de la nueva escuela a las jornadas de junio.}

\section{Resumen}

Las jornadas de junio y las manifestaciones realizadas en Brasil en 2015 y 2016 son externalizaciones de deseos profundos de la sociedad por movilidad social, democratización del país y por instituciones más republicanas. En la elaboración de esta pensata se utilizaron informaciones provenientes de tres fuentes de investigación: la bibliográfica, la documental y los medios institucional y alternativa. En este artículo se discutió la propuesta de Anísio Teixeira para implantar la "nueva escuela", una educación pensada para todos como un proceso democrático. En un segundo momento, se discutió también el sentido de lo que se llamó "democratización del acceso" a la enseñanza superior. Por último, se ha trazado un paralelo entre la lucha por la democratización del país en el pasado y en el presente.

Palabras clave: Democratización, Escuela Nueva, Educación Básica y Superior, Jornadas de Junio. 


\section{Introdução}

O Brasil registrou nos últimos quatro anos as maiores manifestações públicas de sua história. Em 2013, a grande reivindicação era a mobilidade urbana, iniciada em São Paulo. Mas, na verdade, com o alastramento das manifestações públicas para todos os estados brasileiros, constatou-se que a reivindicação popular era mais ampla e mais profunda. O povo reivindicava mobilidade social e o fortalecimento da democracia pela implantação de um Brasil republicano, onde o império da lei deve valer para todos os cidadãos. Essas reivindicações ficaram mais claras nas manifestações de 2015 e 2016. De fato, elas têm sido amplas, mas não dispersivas e sem foco. A grande luta é pela democratização da Sociedade brasileira, ainda muito desigual do ponto de vista econômico, político, social e cultural, e do Estado ainda muito oligárquico, autoritário e pouco republicano.

A luta pela democratização do Brasil vem de longa data com avanços e recuos. Neste artigo, faz-se uma reflexão sobre os movimentos democráticos vividos no Brasil que englobam uma luta histórica pela universalização da educação básica de qualidade para todos e pela democratização da educação superior de qualidade, condições necessárias ao nosso desenvolvimento no presente. Fazer essa vinculação das várias fases desta luta é uma questão importante, em primeiro lugar, pela continuidade do movimento. Em segundo, porque a história é a ciência que permite "compreender o presente pelo passado e, correlativamente, compreender o passado pelo presente", segundo Marc Bloch (2001, p. 25). Em terceiro lugar, a democratização do Estado e da sociedade brasileira foi um sonho acalentado e prometido pela constituição cidadã de 1988. No ano que vem, ela completará trinta anos sem realizar aquilo que havia jurado. Como esse sonho jamais será esquecido, ele continua vivo no imaginário dos brasileiros e brasileiras e é inspirador dos movimentos sociais pela democratização da sociedade e do estado brasileiro dos últimos anos. Essa luta desdobra-se em várias frentes porque muitas são as necessidades sentidas pelo povo brasileiro no nosso imenso território. Ultimamente, tem apoiado, com denodo, a Lava-jato por que vê nessa investigação a maior operação contra a corrupção e malversação dos recursos públicos que detonam o país por ser um sistema institucionalizado que mobilizam valores extraordinários que faltam à mesa de determinados funcionários públicos e/ou nos hospitais para os mais necessitados. O povo vê na Lava-Jato a grande oportunidade de se democratizar o estado brasileiro, fazendo com que o império da lei valha para todos. Esta é mensagem dita constantemente pelas reiteradas manifestações públicas ocorridas em todo o país. 
O Estado, como ordenamento jurídico-político, é a instituição que viabiliza o governo de uma cidade, província ou país. Ele existe para servir à sociedade e responder às suas necessidades, aspirações e aos desafios relacionados à sobrevivência do indivíduo e da comunidade. A relação - Estado e Sociedade - constitui um sistema complexo em que um não existe sem o outro e a natureza desta relação é que vai determinar o seu sentido e os resultados esperados.

Nessas interações, as mudanças trazidas pela sociedade fazem com que o ser humano passe a refletir sobre sua condição, pois a troca de informações e o grande fluxo de conhecimentos modificam as nossas ideias sobre a vida, o universo e o próprio homem. Nesta perspectiva, Morin (2004) ressalta, ainda, a importância das universidades como fontes perenes e abundantes do conhecimento humano, já que sua produção, voltada para o enriquecimento da ciência, destrói mitos e afasta o indivíduo do senso comum, normalmente contaminado por uma doutrina social dominante em voga. O homem é, por si mesmo, capaz de aprofundar suas ideias, repensar suas próprias questões, mudar o seu comportamento e promover evoluções.

A mudança de comportamento passa necessariamente pela conscientização dos indivíduos e, neste processo, destaca-se o sistema educacional. Quando a educação está em crise, o movimento social pouco avança. A educação é o principal sustentáculo do alicerce social. Sem ela, o risco de retorno ao estado de natureza é muito elevado.

O Brasil foi descoberto por um país de cultura conservadora de fundamento religioso e tornou-se uma "colônia de exploração". Segundo Cunha (2007, p. 22) "A colonização consistia, basicamente, na organização de uma economia complementar à da Metrópole". O País herdou do período colonial valores e práticas de domesticação, tendo por base um sistema escravocrata, causador da destruição de várias nações indígenas. Posteriormente, foi incorporada uma grande massa de negros, trazidos da África e engajados na produção colonial de exportação. Mesmo, após a nossa independência, não houve uma preocupação maior com o desenvolvimento intelectual do nosso povo nem com a criação de um mercado interno que viabilizasse nosso desenvolvimento.

Essa herança foi assim resumida por Anísio Teixeira:

O poder monárquico, para impedir qualquer desenvolvimento autônomo da terra brasileira, fecha sua fronteira, torna obrigatória a naturalidade portuguesa dos funcionários, monopoliza o comércio e nega permissão em suas novas terras para a fábrica, a tipografia, a imprensa e a universidade, pondo assim a Colônia em estreita dependência da Metrópole que ela afinal, de certo modo, se integra - com a sua nobreza, o seu clero e o grupo de burocratas e letrados todo 
ele formado na Metrópole - ao pequeno e poderoso Portugal (Teixeira, 2005, p.123).

Por todo este período a educação brasileira ficou restrita, em primeiro lugar, em Coimbra, no período colonial e depois em algumas poucas faculdades durante todo o império, tendo, como consequência, a formação de uma "elite caracterizada pela homogeneidade ideológica, propiciadas pela educação, pela ocupação e pela carreira política.” (Cunha, 2007, p. 13).

A universidade no Brasil surgiu no século XX cerca de cem anos após a nossa independência, com grande atraso em relação a outros países, fato este com grandes repercussões até os dias atuais, segundo Cunha (2007).

Neste contexto, como pensar uma educação transformadora que rompa com o processo de domesticação ou condicionamento do nosso passado colonial? Como torná-la um processo relacional que objetiva preparar as pessoas ou fazer com que elas adquiram uma forma própria de pensar e de conduzir suas vidas? Não seria também histórica a falta de interesse por parte dos governantes de que as pessoas tomem na mão a condução de sua própria vida, ou seja, tornem-se senhores de si? O quão importante é o investimento de uma nação em educação e em possibilitar o acesso de seus jovens à educação de qualidade?

A democratização do acesso à educação e a garantia de qualidade na educação são grandes desafios a serem enfrentados pelo país, da educação básica à educação superior. Estes temas foram amplamente discutidos por Anísio Teixeira, comprometido com a formação de uma sociedade democrática por meio da educação. A conquista de uma sociedade democrática continua a ser um desafio a mobilizar a sociedade brasileira no presente por meio das mais variadas manifestações sociais e pelo uso das novas mídias alternativas.

Esta pensata, além da introdução, está dividida em três partes. Na segunda, discute-se a democratização da educação básica na perspectiva de Anísio Teixeira como condição primeira da cidadania e da implantação do regime democrático no país.

A terceira parte é dedicada à discussão da democratização do ensino superior nos anos mais recentes como fator do nosso desenvolvimento e da democratização da nossa sociedade no presente. Na quarta parte, as considerações finais, faz-se um balanço desses dois movimentos, vinculando-os com as mobilizações e as aspirações democráticas da atualidade, próprias de uma sociedade do conhecimento e de um mundo globalizado.

\section{Metodologia}


Na elaboração desta pensata foram usadas informações provenientes de três fontes de pesquisa: a bibliográfica, a documental e a mídia institucional e alternativa. A bibliográfica tem por base a literatura especializada sobre a problemática analisada, produzida no passado e no presente. A documental refere-se à pesquisa em fontes primárias e secundárias relacionadas ao tema. Nas mídias institucionais e alternativas e em pesquisas feitas com manifestantes foram levantados dados que permitem analisar as mobilizações populares pela democratização do estado e da sociedade brasileira nos anos mais recentes (Cidades Rebeldes, 2013 e Silva, 2014).

\section{Anísio Teixeira e educação básica: a escola preparando para a Democracia.}

Os graves problemas da educação Brasileira presentes nos anos iniciais do século XX, dentre eles a falta de acesso de grande parte da população à educação básica quando apenas $9 \%$ das crianças em idade escolar frequentavam a escola, levaram Anísio Teixeira, um dos mais importantes pensadores da educação no país, a refletir sobre as políticas públicas de educação para o Brasil.

A matriz de pensamento deste educador/pensador era o da construção de uma sociedade democrática por meio da educação, concebendo-a como um recurso para sua modificação e para o resgate do indivíduo.

Anísio Teixeira se incluía entre os modernistas cuja missão, autoproposta, era a reconstrução nacional, destacada aí a fundamental ação da escola.ș̣p:A ideia de escola como um processo de cultura, de estímulo à mudança permanente e de meio de reconstrução social percorre seu pensamento e sua obra é dedicada à mudança da escola para mudar a sociedade, fazendo-a ingressar na civilização industrial moderna (Evangelista, 1993, p. 87).

Anísio entrou em contato com outras experiências buscando modelos educacionais estrangeiros e trouxe dos Estados Unidos as ideias de Dewey, especialmente no que diz respeito a uma nova metodologia de ensino, com uma evidente preocupação na sua modificação não em termos do conteúdo, mas na forma de ensinar. Anísio Teixeira inspirou- se nas ideias de John Dewey no seu: “...pensamento pedagógico e, particularmente, sua filosofia social, que iriam se constituir, a partir daquele momento, na referência central que iria nortear a sua atuação pública no campo educacional.” (Romão, 2011, p. 16)

Da experiência e estreito contato com educadores nos Estados Unidos, Anísio compartilhou suas ideias como a "...função permanentemente social da educação que ele partilhou com aquela plêiade de educadores americanos, função social esta com que Anísio abre caminho para a longa marcha que o aguardaria e que tanto beneficiou nosso país." (Benathar, 
1981, p. 1662)

Na escola que Anísio propõe na perspectiva Deweyana, “... aprender significa bem mais do que fixar, compreender e exprimir verbalmente um conhecimento. Aprender implica, necessariamente, na aquisição de um novo modo de agir e, por conseguinte, só se aprende aquilo que se pratica” (Romão, 2011, p. 28). Vê-se nesta afirmação uma preocupação com a prática constante. Não a prática pela prática, mas a observação da prática.

Para Dewey a educação “...visa manter e renovar a comunidade, operando a transmissão da experiência e a reconstrução de práticas e valores coletivos.” (Dewey, 2007, p. 8). Para ele, somente em uma sociedade democrática poderíamos fazer com que estes objetivos da educação fossem realmente efetivados e para todos os indivíduos, pois a ideia de habilitar a todos para que tenham um desenvolvimento constante, somente poderia ser aplicada quando existe uma relação de interesses estimulados de forma equitativa, o que só ocorre em uma sociedade democrática (Dewey, 2005).

À época a educação no Brasil só privilegiava as classes sociais mais favorecidas: a oligarquia e os religiosos. Para as classes populares restava uma educação doméstica e o aprendizado do ofício, passado dos pais para os filhos. Em suas palavras:

A sociedade formava os homens nas próprias matrizes estáveis das "classes" senão "castas", instituições que incorporavam a família e a religião, com as suas forças modeladoras e adaptadoras. Formado assim o homem, as aprendizagens mais específicas, relacionadas com o trabalho, se faziam pela participação direta na vida comum, ou, no caso de artesanato, pelo regime do mestre e aprendiz nos ateliers e oficinas da época (Teixeira, 1989, p. 435).

Para Anísio Teixeira, esta realidade poderia ser modificada por meio da democratização da sociedade brasileira pela democratização do acesso à educação, uma educação que a prepararia para a democracia. Nas palavras do pensador: "só existirá uma democracia no Brasil no dia em que se montar no Brasil a máquina que prepara as democracias. Essa máquina é a escola pública." (Teixeira, 1953, p. 205)

A municipalização do ensino é uma de suas teses mais brilhantes, segundo Benathar (1981).

A regionalização da escola que, entre nós, se terá de caracterizar pela municipalização da escola, com administração local, programa local e professor local, concorrerá em muito para dissipar os aspectos abstratos e irreais da escola imposta pelo centro, com programas determinados por autoridades remotas e distantes e servida por professores impacientes e estranhos ao meio, sonhando perpetuamente com redentoras remoções (Teixeira, 1989, p. 458).

A escola integral é outra ideia central de sua proposta, objetivando a democratização da escola e, por meio dela, da sociedade brasileira. No dizer de Romão: "Para Anísio Teixeira, apenas a escola pública, gratuita, universal e obrigatória, estatal e laica, poderia se constituir 
em uma escola verdadeiramente democrática.” (Romão, 2011, p. 26)

Neste momento, não se pensava em como a educação contribuiria para o crescimento pessoal e social dos alunos, mas na sua inclusão na escola. Anísio defende uma instituição pública articulada com a comunidade. Pensou-se em uma escola integral para a formação da inteligência do indivíduo e sua iniciação ao trabalho. Esta formação seria a responsabilidade primeira da escola básica no pensamento de Anísio Teixeira.

O educador brasileiro não pensa em uma escola para inclusão do pobre de forma que este se iguale ao rico, mas para que ricos e pobres estivessem diante das mesmas oportunidades. Por isto, propunha uma educação para todos, trabalhadores e intelectuais:

Em fase da aspiração de educação para todos e dessa profunda alteração da natureza do conhecimento e do saber (que deixou de ser a atividade de alguns para, em suas aplicações, se fazer a necessidade de todos, a escola não mais poderia ser a instituição segregada e especializada de preparo de intelectuais ou "escolásticos". Deveria transformar-se na agência de educação dos trabalhadores comuns, dos trabalhadores qualificados, dos trabalhadores especializados em técnicas de toda ordem, e dos trabalhadores da ciência nos seus aspectos de pesquisa, teoria e tecnologia (Teixeira, 1989, p. 440).

No entanto, do ponto de vista prático, não houve uma preparação adequada para receber o novo aluno, um ser especial descendente de escravo ou de índio que trazia consigo diferenças étnicas, sociais e culturais significativas se comparado aos estudantes de estratos sociais superiores que frequentavam a escola à época. O projeto da "nova escola" envolveria necessariamente a preparação de um novo professor, figura fundamental para o sucesso do novo empreendimento. A reforma integral da formação do professor era fundamental. No papel de reconstrução da nação pela escola, como acreditava Anísio, o professor era a figura central neste processo de transformação da sociedade brasileira. Para que a escola se transformasse, as pessoas precisariam se preparar para que esta transformação ocorresse.

Quando se iniciou o processo de democratização do acesso à escola primária no Brasil, esta não ocorreu pelo viés do direito à educação para todos. A escola expande-se física e massivamente, mantendo-se, porém, refém de práticas próprias de uma escola tradicional com seu padrão elitista. Pode-se inferir que o acesso à escola se expande, mas ela não se democratiza.

A escola cresce, mas continua com os seus portões fechados.

A escola primária começou a expandir a partir da década de 20, mas, na verdade, sem se adaptar para um aumento da oferta nem se modernizou espacialmente. Continuou o "ajeitamento": junção de turnos, aproveitamento de espaços reduzidos, diminuição de anos de estudo para que os novos alunos pudessem entrar e outros jeitinhos para que a determinação da 
norma legal fosse cumprida, sem provocar uma mudança real na escola primária com a ampliação do acesso na direção apontada por Anísio Teixeira. Este havia proposto uma escola integral, formadora, democrática, equipada e para servir à comunidade. Uma escola nova, verdadeiramente inovadora.

As escolas refletiram, assim, de acordo com o velho estilo, o dualismo social brasileiro, entre os "favorecidos" e os "desfavorecidos". Por isso mesmo, a escola comum, a escola para todos, nunca chegou, entre nós, a se caracterizar, ou a ser de fato para todos. A escola era para a chamada elite. O seu programa, o seu currículo, mesmo na escola pública, era um programa e um currículo para "privilegiados". Toda a democracia da escola pública consistiu em permitir ao "pobre" uma educação pela qual pudesse participar da elite (Teixeira, 1989, p. 451).

Para esta nova escola, não seriam mais adequados os velhos métodos próprios da escola medieval ainda em uso no ensino primário com suas atividades baseadas na exposição oral e na simples reprodução de conceitos existentes. No funcionamento das atividades diárias, não havia preocupação com o caráter prático da formação pelo trabalho e pela ação, requeridos pela nova proposta de educação formulada por Anísio Teixeira.

$\mathrm{Na}$ verdade, era necessário formar as pessoas para que esta expansão acontecesse da forma como foi idealizada. Além da inovação que representava na ocasião a escola para todos, "a própria educação escolar tradicional ainda existente teria que se transformar", segundo Teixeira (1989, p. 436), para que a "nova escola" fosse implantada e se expandisse por todo o país.

Já na década de 1920, houve certa expansão da matrícula na escola primária, frequentada por um aluno vindo de estratos sociais diferenciados, porém, o sistema escolar continuou o mesmo. Nas palavras de Anísio:

Esta pedagogia podia perfeitamente funcionar numa escola da Idade Média. A sua filosofia do conhecimento é a de que o conhecimento é um corpo de informações sistematizadas sobre as coisas, que se aprendem, compreendendo-as e decorando-as para a reprodução nos exames (Teixeira, 1989, p. 442).

O avanço maior ocorreu nas décadas seguintes no campo da legislação escolar à medida que o país se urbanizava e se industrializava. Assim, a promulgação da Lei n. 9.394 de 20 de dezembro de 1996, Lei de Diretrizes e Bases da Educação Nacional - LDBEN, não só revogou a Lei n. 5.692, de 11 de agosto de 1971, que já definia a educação como um "dever da União, dos Estados, do Distrito Federal, dos Territórios, dos Municípios, das Empresas, da Família e da comunidade em geral". Ela explicitou melhor o que se entende por educação como dever do Estado, no seu artigo 4o em seus vários incisos. Segundo a LDBEN, o Estado deve garantir:

I - ensino fundamental, obrigatório e gratuito, inclusive para os que a ele não tiveram 
acesso na idade própria;

II - progressiva extensão da obrigatoriedade e gratuidade ao ensino médio;

III - atendimento educacional especializado gratuito aos educandos com necessidades especiais, preferencialmente na rede regular de ensino;

IV atendimento gratuito em creches e pré-escolas às crianças de zero a seis anos de idade;

VIII - atendimento ao educando, no ensino fundamental público, por meio de programas suplementares de material didático-escolar, transporte, alimentação e assistência à saúde;

IX - padrões mínimos de qualidade de ensino definido como a variedade e quantidades mínimas, por aluno, de insumos indispensáveis ao desenvolvimento do processo de ensino-aprendizagem.

A legislação é bem detalhada e prevê uma série de dispositivos e iniciativas que não se concretizaram ainda e é bem provável que não se concretizem tão cedo como aconteceu com outras leis aprovadas no passado que dizem respeito à Educação e a outros campos. Mas mesmo assim não se pode perder o costume nacional de se mudar a realidade por meio de novas leis promulgadas a cada dia.

Atualmente, verifica-se uma disputa intensa por vagas nas escolas públicas, pois o número de vagas está sempre abaixo do que a demanda exige. Como não se pode matricular uma criança longe de casa porque nem sempre se pode contar com um transporte de qualidade, uma relação adequada entre a demanda existente e a necessidade fica, quase sempre, comprometida.

Além destas, há outras questões práticas relacionadas a vagas, transporte público, alimentação, dentre outras. Para que estas boas ideias fossem transformadas em realidade, seria de fundamental importância a consideração da educação no seu sentido mais amplo e sua inserção na sociedade pode se dar de diversas maneiras. $\mathrm{O}$ homem, como ser vivente, educa-se com o que ouve, com o que sente, com o que vê, e, ainda, com o que processa de tudo isto, podendo-se inferir que sua educação é a soma do que conseguiram reunir seus sentidos sensoriais, nas asas de sua inteligência, imaginação e sensibilidade. A mistura de tudo isto trazlhe a paisagem final de seu processo, de sua visão, de si e de tudo que compõe o seu ambiente de vida. Partindo-se desta constatação, pode-se afirmar que tudo é importante para a formação do ser humano: a escola, a família, a saúde, os amigos, o trabalho, enfim, tudo que o cerca e o transforma.

Assim a educação básica deve ser pensada, considerando-se toda a estrutura necessária para a formação humana e todo o seu entorno. A escola não pode pensar apenas no projeto de 
ensino, mas também no projeto de formação que envolve formar as pessoas para que sejam capazes de conduzir a própria vida, ou seja, para que se tornem senhores de si.

\section{Democratização do acesso ao ensino superior: excluídos por fora e por dentro}

A expansão da Educação Superior ocorrida no Brasil a partir do final do século XX como processo, assemelha-se bastante com a proposta de democratização do acesso à educação primária pensada por Anísio Teixeira.

Além do ensino primário, Anísio teve uma grande atuação na expansão da educação superior no país, iniciando pela sua participação na criação da Universidade do Distrito Federal (UDF) em 1935. Posteriormente, destacou-se na organização da CAPES e da Universidade de Brasília, juntamente com Darcy Ribeiro e outros. Participou, também, da fundação do Conselho Federal de Educação e do Instituto Nacional de Estudos Pedagógicos (INEP) com seus Centros Regionais de Pesquisa Pedagógica em diferentes Estados da Federação, segundo (Benathar, 1981). Hoje, é denominado Instituto Nacional de Estudos e Pesquisas Educacionais Anísio Teixeira em sua homenagem. O INEP, sob o comando de Anísio, destacou-se como instituição de pesquisa sendo responsável pela organização da maior biblioteca pedagógica do país.

A CAPES comemorou, em 2016, 65 anos de existência e há na instituição um Prêmio Capes "Anísio Teixeira", honraria que muito dignifica quem o recebe por contribuir com o desenvolvimento da educação no país. Anísio lutou pela valorização da educação pública como direito e se afastou da vida pública nos tempos em que a ditadura do Estado Novo, em 1937, secundarizou a educação pública. O educador voltou à vida pública em 1946, oferendo uma grande contribuição para a educação superior com a fundação da CAPES, em 1951, sendo o seu primeiro dirigente.

Dentro da Universidade, na visão de Anísio, deveriam formar-se os intelectuais, responsáveis por conduzir a sociedade. Ali deveria construir-se a “...cultura expressiva das sociedades contemporâneas, de base científica e tecnológica”, segundo Romão (2011, p. 36). Pela sua feição clássica, a universidade, como o lugar do pensamento, deveria ser um centro de investigação e pesquisa científica, ideia fortemente defendida pelo educador brasileiro. Com a proposta de uma universidade de ciência e pesquisa, Anísio ressaltava a necessidade de investimento na formação docente, transformando o ambiente acadêmico por meio da pósgraduação. A visão do educador era uma visão clássica do modelo humboldtiano, caracterizado pelo foco na investigação, na pesquisa nas ciências naturais e humanas, com enfoque no desenvolvimento da nação e do indivíduo, visando à "formação dos jovens acadêmicos como 
cidadãos responsáveis." (Goergen, 2014, p. 566)

No entanto, quando se analisa o processo concreto de democratização do ensino superior brasileiro, questiona-se se esta proposta foi implementada como havia sido concebida. Reconhece-se certo desvirtuamento no seu processo de implementação como sucedera com o projeto de democratização do acesso ao ensino fundamental planejado por Teixeira.

No que diz respeito ao ensino superior, deve-se ressaltar que a universidade no Brasil surgiu com muito atraso em relação aos outros países, desenvolvidos ou emergentes. Só ocorreu um século depois de nossa independência.

No final do século XIX quando iniciou o processo de industrialização por substituição de importações, o Brasil recorreu à imigração europeia como estratégia de suprimento da mão de obra especializada necessária à indústria. Os nativos e os libertos ficaram largados à própria sorte. A partir de 1955, o Brasil alterou seu modelo de desenvolvimento, optando pela atração de capitais estrangeiros para implementar sua indústria na área de bens de consumo durável, começando pela fabricação de automóveis e, depois, pela linha branca, televisores e outros produtos eletrônicos. ${ }^{i}$ Com esta decisão, o Brasil passou a dar preferência à importação de ciência e tecnologia do que desenvolvê-las aqui. Esta política continua no presente, devendose registrar algumas ilhas de excelência existentes espalhados pelo país. Ainda hoje é pouco desenvolvida a pesquisa de ponta em comparação ao que se empreende nos países mais desenvolvidos e entre os emergentes. A nossa pauta de exportação continua sendo formada por primários com baixo valor agregado.

A expansão da educação superior iniciou a partir de 1945 em função do crescimento da classe média e da maior urbanização e industrialização do país. Com a demanda interna maior, o número de instituições cresceu significativamente e o Brasil passou de três universidades em 1930 para 39 universidades em 1964. Segundo Marques:

No período que vai de 1945 a 1964, a sociedade brasileira viveu um tempo de liberdades democráticas quando intelectuais, professores e estudantes vinculados à União Nacional de Estudantes (UNE) e Sociedade Brasileira para o Progresso da Ciência (SBPC) atuavam fortemente em direção à democratização da educação, gestando neste período propostas inovadoras para a educação superior (Marques, 2013, p. 69).

$\mathrm{Na}$ década de 70 este crescimento foi ainda mais acentuado e surgiram inúmeras universidades e faculdades com a ampliação das instituições particulares, abrindo-se as portas para a proliferação das instituições privadas de educação superior no país. Esse processo cresceu a partir de 1990 com a inserção do Brasil no cenário mundial, com a privatização da 
economia e a redução da capacidade de investimento do Estado. Ocorreu um aumento significativo do investimento privado na educação superior, do número de instituições de ensino e de vagas para o ensino superior.

Neste momento, grandes grupos empresariais entram para o setor educacional distanciando-o da ideia de educação como um bem público e, com o novo viés, perde espaço a educação voltada à sociedade, mas crescendo em iguais proporções sua dimensão associada ao mercado. A educação superior, idealizada por Anísio com a função de formar intelectuais que deveriam conduzir a sociedade, dá lugar à educação concebida como treinamento profissional. No dizer de Dias Sobrinho (2010, p. 1225) "Quando não compreendida como bem público, a educação atende prioritariamente ao indivíduo e a seus interesses exclusivos."

Na última década, segundo dados do Censo da Educação Superior, realizado anualmente pelo Instituto Nacional de Estudos e Pesquisas Educacionais Anísio Teixeira (INEP), a educação superior no Brasil, especialmente no setor privado apresentou um enorme crescimento. ${ }^{\text {ii }}$ Segundo o Censo da Educação Superior de 2010 (INEP/MEC) o Brasil tem 2.378 instituições de ensino superior, das quais $88,3 \%$ são privadas, $4,5 \%$ estaduais, $4,2 \%$ federais e 3,0\% municipais. Destas, 85,2\% são faculdades e instituições isoladas não universitárias; 8,0\% são universidades, 5,3\% centros universitários e 1,6\% institutos federais de educação, ciência e tecnologia (IFs) e centros federais de educação tecnológica (Cefets).

Observa-se, no entanto, uma concentração de vagas nas instituições privadas controladas por poucos grupos empresariais que atuam no ramo. Registra-se, também, uma mudança política que tem ocorrido nas IFES: a retomada do investimento nas universidades públicas federais mediante o credenciamento de novas instituições, a ampliação de vagas e a criação de novos cursos, proporcionando um aumento de $42 \%$ nas suas matrículas na primeira década do século XXI. Esse aumento, no entanto, é muito inferior ao ocorrido nas instituições privadas na mesma época.

A despeito do crescimento registrado, deve-se questionar - da mesma forma como se fez em relação à educação básica - se a expansão da educação superior significou um processo de democratização do acesso, permitindo a inserção de todos, inclusive dos jovens desfavorecidos, que ainda não haviam tido a oportunidade de galgar ao ensino superior. $\mathrm{O}$ aumento do número de escolas e vagas possibilitou uma entrada maior de jovens para a educação superior, porém isto, evidentemente, não garante condições de permanência deste aluno até a conclusão de seu curso nem uma educação de qualidade. Como observa Dias Sobrinho referindo-se a esse propósito: 
É necessário esclarecer desde logo que a "democratização" da educação superior não se limita à ampliação de oportunidades de acesso e à criação de mais vagas. Além da expansão das matrículas e da inclusão social de jovens tradicionalmente desassistidos, em razão de suas condições econômicas, preconceitos e outros fatores, parece ser imprescindível que lhes sejam assegurados também os meios de permanência sustentável, isto é, as condições adequadas para realizarem com boa qualidade os seus estudos. Assim, acesso e permanência são aspectos essenciais do processo mais amplo de "democratização" (Dias Sobrinho, 2010, p. 1226).

Tem-se, atualmente, um número grande de "pretendentes" ao ensino superior. Porém, muitos não saem dessa pretensão, por não encontrarem condições de permanência neste nível escolar. Outros, quando conseguem entrar, não permanecem, mesmo sendo alunos de uma instituição pública, o que confirma a hipótese de que ampliar o acesso sem criar condições para que o aluno nele permaneça e se forme com qualidade não garante uma real democratização pretendida com sua expansão no país.

O acesso sem permanência pode representar, ao contrário, uma barreira ainda maior para que este aluno tenha uma real oportunidade de mobilidade social conquistada pela conclusão de um curso superior. Sua exclusão da universidade por falta de condições de permanência vai dificultar seu ingresso ou sua permanência no sistema produtivo, cada vez mais competitivo. Pode produzir, em consequência, baixa estima e pouco comprometimento com a sociedade que lhe fechou as chances de ascensão social.

A expansão do ensino superior não garantiu oportunidades para todos como bem observa Martins:

De 1990 a 2002, a demanda por educação superior, expressa através do número de inscrições no vestibular, cresceu aproximadamente em $160 \%$ e a oferta de vagas aumentou para $252 \%$. A expansão da oferta contribuiu para a redução do número de candidatos por vagas. No entanto, o ensino público continuou sendo o mais procurado, ...ao passo que o ensino privado acusou, no mesmo período, uma redução de 2,9 para 1,6 candidatos. Não obstante o expressivo crescimento das matrículas nos cursos de graduação... existem indícios de que a política de expansão através da via privada começa a dar claros sinais de exaustão: em 2004, 49\% das vagas do setor privado estavam sem ocupação e houve também um aumento significativo do número de estudantes inadimplentes (Martins, 2009, p. 5).

Verifica-se que a expansão do ensino superior e sua privatização não significaram exatamente uma democratização do acesso a este nível de ensino no país, um fenômeno semelhante ao ocorrido com a educação básica proposta à época por Anísio Teixeira. Novamente, neste caso, o sistema de educação superior deveria ter sido preparado para processar esta expansão e para fazer dela um real processo de democratização.

Uma primeira questão a ser resolvida pela universidade seria relacionada à definição do 
seu papel na sociedade atual. Como mencionado ao longo do artigo, são dois papeis diversos que estão em contraposição: pelo primeiro, a educação, como bem público, deveria dedicar-se à formação integral da pessoa humana o que incluiria a preparação para o trabalho e, também, as dimensões sociais, culturais, intelectuais, políticas e ético-morais. Como segundo, a concepção instrumental de educação, que a reduz à sua função meramente econômica e de treinamento para o trabalho.

Percebe-se que se a educação for vista como mercadoria em atendimento aos interesses individuais, a determinação de sua qualidade obedeceria à lógica do mercado e não ao interesse da sociedade. Esta concepção diversa de educação faz toda a diferença quando relacionada ao processo de democratização, definido como possibilidade de acesso, permanência e garantia de sua qualidade.

A resolução deste dilema, vivido pela sociedade atual, é fundamental para a definição do modelo de universidade que se pretende implantar e, consequentemente, para o tipo de aluno que se deseja formar. Há, hoje, uma demanda generalizada quanto ao papel educativo que a universidade deveria cumprir. Com base em certa visão, espera-se tudo dela: a resolução dos problemas da política, da economia, da moral e outros problemas da vida cotidiana. Como observa Dias Sobrinho a esse respeito:

... importantes problemas da educação não serão resolvidos no interior das instituições e dos sistemas educativos. São problemas que conformam a crise geral dos nossos tempos, constituída, entre outros aspectos, pela perda de referências de valor, explosão da informação e dos conhecimentos, rápida obsolescência dos produtos, mudanças nos perfis profissionais, obsessão consumista, individualismo, incertezas quanto ao futuro, economia como princípio regulador da sociedade, etc. (Dias Sobrinho, 2010, p. 1225).

Quando se propõe a resolução deste dilema é o momento de parar para pensar, que tipo de universidade se pretende ter e, também, que tipo de sociedade se objetiva construir ou que tipo de homem será preciso formar.

A implementação da universidade, idealizada por Anísio, para formar intelectuais responsáveis por conduzir a sociedade e para criar uma cultura de base científica e tecnológica, para que aconteça, deveria garantir uma organização que possibilitasse a construção deste modelo ideal.

No entanto, quando se observam os problemas existentes na sociedade atual, constatase que a expansão do ensino superior não garantiu a "democratização" do acesso nem a formação adequada do jovem e do cidadão que o país precisava. Mesmo com a expansão ocorrida no ensino superior, considera-se este crescimento muito pequeno medido por dois 
parâmetros distintos. Pelo primeiro, o Brasil só tem, aproximadamente, $15 \%$ da sua população matriculada na educação superior. Pelo segundo, faz-se uma comparação em termos de matrículas no ensino universitário com aquilo que ocorre em outros países. Como afirma Moura (2003, p. 32) “...há países em que 70 ou $80 \%$ dos jovens com idades compreendidas entre os 18 e 24 anos frequentam estudos superiores." Diante disto, constata-se que é, ainda, longo o caminho que precisamos percorrer.

Além disso, deve-se considerar que a educação superior no Brasil foi implantada com deficiências históricas no período colonial e um empobrecimento dos modelos importados por ela. A “escola superior” passou longe do modelo idealizado por Anísio. A sociedade colonial brasileira impôs seus próprios padrões e seu ritmo ao modelo importado da metrópole (que já era um modelo considerado atrasado considerando o cenário europeu), não tendo sido este utilizado em sua total potencialidade, mas ajustado ao que era possível se obter dele na ocasião.

Sob este aspecto, a transplantação de instituições da sociedade metropolitana esbarrava em um vazio histórico, que era criado pela própria estrutura social de uma sociedade colonial escravista e senhorial. Esta não oferecia às instituições absorvidas socialmente um patamar históricocultural equivalente ao da sociedade metropolitana (Fernandes, 1975, p.97).

Segundo Fernandes (1975), este empobrecimento do modelo importado da metrópole se deu por três razões. A primeira delas refere-se ao número reduzido de escolas; os corpos docente e discente, formados por pequenos grupos institucionalizados de professores e alunos recrutados das elites da sociedade e, por fim, as dinâmicas do isolamento cultural das instituições de educação superior, o que as torna muito similares e, consequentemente, com um padrão muito definido em atendimento de um único propósito.

Ela não foi posta em causa através da qualidade de seu rendimento ou sua utilidade. Mas como fonte de reconhecimento social do talento de jovens já incorporados e classificados no seio da sociedade civil. A sociedade não valorizou o ensino superior, como e enquanto tal; porém, o que entendia ser o seu produto final, nas realizações pessoais (Fernandes, 1975, p. 99).

Todo este desenvolvimento dependente traz efeitos educacionais que, embora muitos anos tenham se passado, deixam marcas estruturais nos padrões institucionais e impactam em ações do dia-a-dia.

\section{Considerações finais}

Pelo exposto ao longo da pensata, percebe-se que o sonho acalentado para termos uma educação para todos tanto no ensino fundamental como no superior vem sendo pensado no Brasil desde longa data. No entanto, ainda continua sendo uma questão não resolvida a despeito 
da universalização da matrícula no ensino fundamental e do aumento do acesso ao ensino superior. A democratização do ensino e da sociedade pela educação vai muito além da ampliação do acesso, embora o progresso feito neste campo nas últimas décadas deva ser considerado como muito significativo.

A educação superior estava preparada para a grande expansão ocorrida a partir de 1990 ? Não deveria a democratização do acesso à educação superior ser pensada como uma política pública pelo país, com a determinação de ações externas e internas envolvendo o acesso, a permanência e o acompanhamento do aluno até a sua conclusão?

Estas são questões que precisam ter uma discussão ampla densa e que gere resultados para a educação superior no país.

A educação é a base para a difusão do conhecimento e para a formação integral do ser humano e o conhecimento é fator do desenvolvimento econômico e da sociedade global contemporânea. Portanto, garantir educação superior aos nossos jovens é fundamental, pois ali se formam empresários, trabalhadores e líderes, futuros condutores desta sociedade.

Esta educação deve garantir a qualidade na formação destes líderes, por meio de processos de avaliação genuínos e eficientes.

O que se tem hoje no Brasil, embora exista um Sistema Nacional de Avaliação da Educação Superior (uma política de Estado muito bem pensada e não implantada) não pode ser chamado de avaliação, mas de um processo burocrático de fiscalização e controle, o que prejudica sobremaneira o desenvolvimento das instituições. E não há perspectiva de alteração desta prática, que não pode atestar a qualidade das instituições e seus cursos, pois não conta com elementos de análise suficientes para tanto.

Deve-se pensar, ainda, nos recursos destinados à educação, que não são suficientes para que a escola se prepare para receber o aluno que nunca esteve por lá. A preparação deve ocorrer por meio de ações, como: capacitação de professores e do corpo técnico- administrativo das escolas; reestruturação das propostas acadêmicas; investimento em pesquisa, projetos de extensão, infraestrutura física e de apoio ao aluno; recuperação dos valores da escola; ampliação do relacionamento social da escola; apoio à inovação; ampliação da participação ativa das escolas na criação de políticas públicas para a educação.

O que se busca é a perspectiva da formação de um país, com uma proposta própria e autêntica para seu sistema educacional, por meio de uma mudança estrutural que garanta o nosso desenvolvimento e a formação de uma sociedade mais democrática e igualitária.

A educação precisa de políticas públicas que garantam o seu desenvolvimento, livrando- 
se de uma prática que parece ser muito comum no Brasil, a prática do "é melhor que nada". Não é bom, mas é "melhor que nada". O ProUni resolve a questão da inserção? Não. Mas é "melhor que nada". Melhor ter um pequeno percentual se beneficiando com o ProUni do que não ter nada. A avaliação ocorre conforme está proposta no SINAES? Não. Mas é "melhor que nada". Melhor ter uma avaliação que não corresponde ao que foi proposto e que faz com que as IES corram atrás do mínimo do que não ter avaliação. E com esta prática vários assuntos importantes deixam de ser cuidados e dão lugar a ações paliativas, por meio de políticas de governo que trazem uma solução parcial para questões fundamentais que precisariam ser tratadas por meio de políticas de Estado.

O contexto atual do país e do mundo é outro. Estamos no Século XXI em plena globalização e vivendo a quarta revolução industrial. A luta pela democratização do país ainda não se esgotou no plano educacional, no ensino fundamental, médio ou superior. Mas é preciso reconhecer que a luta pela democratização extrapolou os bancos da escola e ganhou as ruas do país desde as Jornadas de Junho de 2013. A luta pela democratização provocou o fim do regime militar e passou pela anistia, pelas "diretas já" e pela constituinte. O movimento democrático na atualidade vem num crescendo. Ao ganhar as ruas de norte a sul e de leste a oeste, a luta pela democratização da sociedade não é mais tarefa direta da escola em qualquer nível de ensino.

Tornou-se um empreendimento cívico que diz respeito à cidadania brasileira, capitaneado pelos movimentos e pelas redes sociais. ${ }^{\text {iii }}$ É um movimento sem volta. Sem dono. Não é passível de manipulação nem de cooptação. Para chegar até aqui foi necessário um longo aprendizado. Certamente, o movimento pela "nova escola" de Anísio Teixeira, pela universalização ao acesso ao ensino fundamental e pela ampliação do ensino médio e superior deu, dá e dará a sua contribuição porque o papel da educação de qualidade não termina aqui. A educação de qualidade é promotora da cidadania e sustentáculo do regime democrático. Uma não vive nem se desenvolve sem a outra.

Nesse movimento pela democratização deve-se mencionar a importância da Lava-Jato, a maior e mais bem sucedida experiência de combate à velha política oligárquica e patrimonial e à corrupção no Brasil. Vale dar aqui o devido destaque à formação profissional dos nossos delegados, procuradores do ministério público e juízes do nosso judiciário e à sua autonomia funcional por terem sido escolhidos por concursos públicos que valorizam a competência e a meritocracia. Por fim, deve-se reconhecer que a Lava-Jato se tornou hoje uma bandeira do movimento popular pela mobilidade urbana e pela democratização da sociedade brasileira nas 
suas mais diversas instâncias e rincões. O movimento pela democratização nascido na escola tornou-se um processo popular e essa luta é irreversível.

\section{Referências}

Bacha, E., \& Bolle, M. B. (2013). O Futuro da Indústria no Brasil, Desindustrialização em Debate. Rio de Janeiro: Civilização Brasileira.

Baer, W. (2002). Economia Brasileira. São Paulo: Nobel.

Benathar, R. L. (1981). Lugar e posição de Anísio Spínola Teixeira na pedagogia brasileira. Rio de Janeiro: Ciência e Cultura, v. 33, n. 12, 1662-1665.

Bloch, M. (2001). Apologia da História ou O Ofício de Historiador. Rio de Janeiro: Jorge Zahar Ed.

Cardoso, R. M. (2015). Avaliação e Acreditação no Desenvolvimento da Educação Superior no Brasil. (Tese de Doutorado em Educação, Universidade de Sorocaba, Sorocaba, SP, Brasil).

Cunha, L. A. (2007). A universidade temporã: o ensino superior, da Colônia à Era Vargas. (3a ed.). São Paulo: Editora UNESP.

Dewey, J. (2007). Democracia e educação: capítulos essenciais. São Paulo: Ática, 1859- 1952.

Dias Sobrinho, J. (out./dez., 2010). Democratização, qualidade e crise da educação superior: fases da exclusão e limites da inclusão. Educ. Soc., Campinas, vol. 31, no. 113.

Ermínia, M. et al. (2013). Cidades Rebeldes, Passe Livre e as Manifestações que tomaram as ruas do Brasil. São Paulo: Bontempo, Carta Maior.

Evangelista, O. (1993). Anísio Teixeira e a educação: um roteiro possível de leitura (19301950). Revista Perspectiva. Florianópolis. V.11, n. 20, 87-125.

Fernandes, F. (1975). Universidade brasileira: reforma ou revolução? São Paulo: Alfa- Omega. Giroletti, D. A. (2002). Fábrica: Convento e Disciplina. (2a. ed.). Brasília: EdUnB.

Lei n. 9.394. (1996, 20 de dezembro). Estabelece as Diretrizes e Bases da Educação Nacional. Diário Oficial da União, seção1, 27-833.

Georgen, Pedro (2014). Tecnociência, pensamento e formação na educação superior. Revista de Avaliação da Educação Superior, Campinas; Sorocaba, SP, v. 19, n. 3, p. 545-803, nov.

Marques, W. (2013). Expansão e oligopolização da educação superior no Brasil. Revista de Avaliação da Educação Superior. Campinas; Sorocaba: São Paulo. V. 18, n. 1, 6983.Martins, C. B. (jan./abr., 2009).

Martins, Carlos Benedito (2009). A reforma universitária de 1968 e a abertura para o ensino superior privado no Brasil. Campinas: Educação e Sociedade, Vol. 30, no. 106, jan./abr.

Morin, E. (2004). Os sete saberes necessários à Educação do futuro. São Paulo: Cortez, Brasília: UNESCO.

Moura, J. B. (2003). Educação Superior: direito ou mercadoria? Revista Rede de Avaliação Institucional da Educação Superior, v.8, n.4.

Onofre, R. (2017, março 22). "Foi a Lava-Jato que fez". Revista Veja, 49-53.

Romão, J. E. (2011). Educadores brasileiros do século XX. In J. E. Romão. (Org.) Brasília: Liber Livro.

Silva, R. H. A. (2014). Ruas e Redes, Dinâmicas dos Protestos BR. In R. H. A. Silva. (Org.). Belo Horizonte: Autêntica Editora.

Teixeira, A. S. (1953). Educação para a democracia: introdução à administração educacional. (2a ed.). São Paulo: Nacional. 
Teixeira, A. S. (1989). Educação não é privilégio. Revista Brasileira de Estudos Pedagógicos. Brasília. V. 70, n. 166, 435-462.

Teixeira, A. S. (2005). Ensino superior no Brasil - análise e interpretação de sua evolução até 1969. Rio de Janeiro: UFRJ.

Relatório para a UNESCO da Comissão Internacional sobre Educação para o Século XXI. (2000). Educação: um tesouro a descobrir. São Paulo: Cortez; Brasília: UNESCO. 